
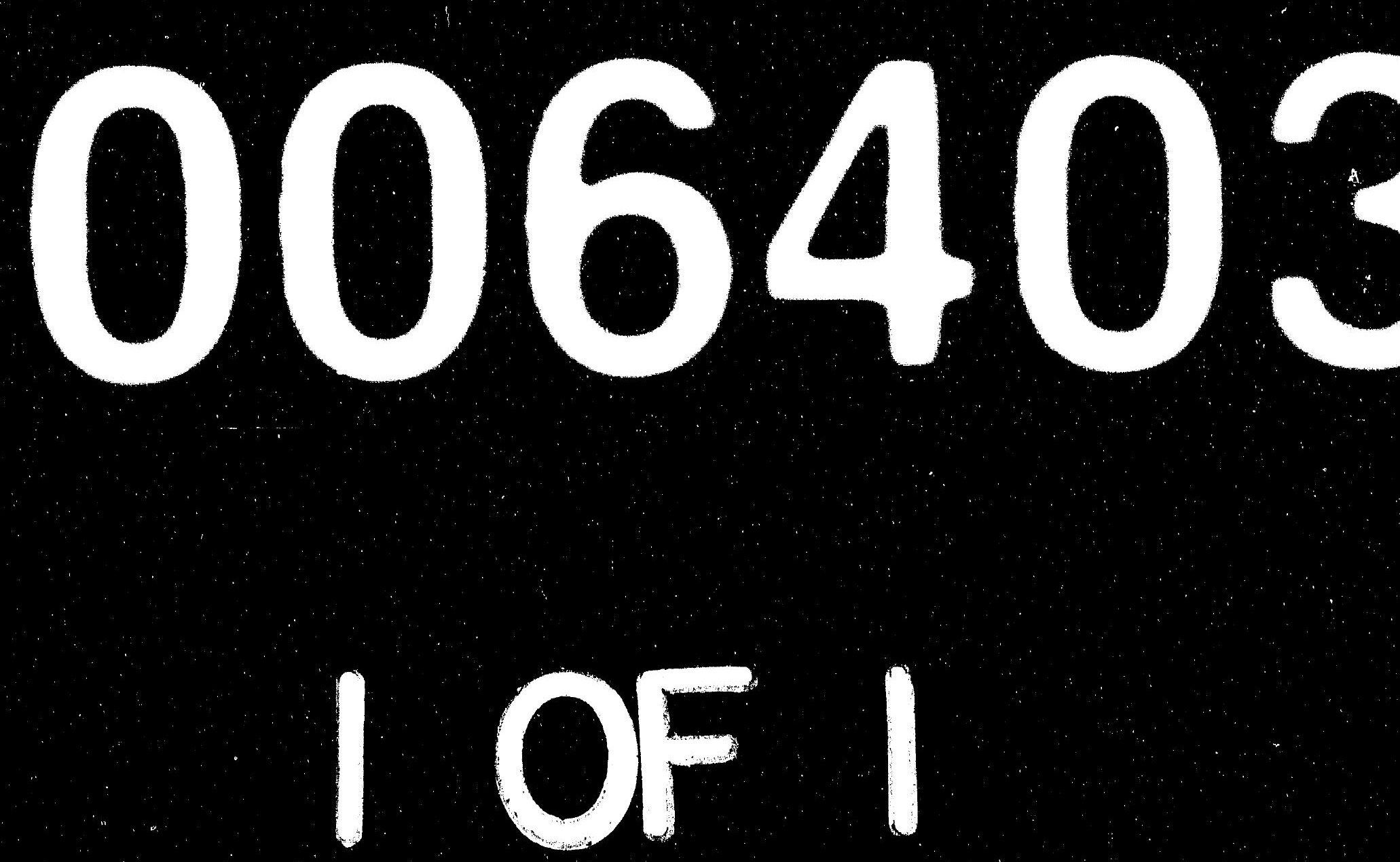

0
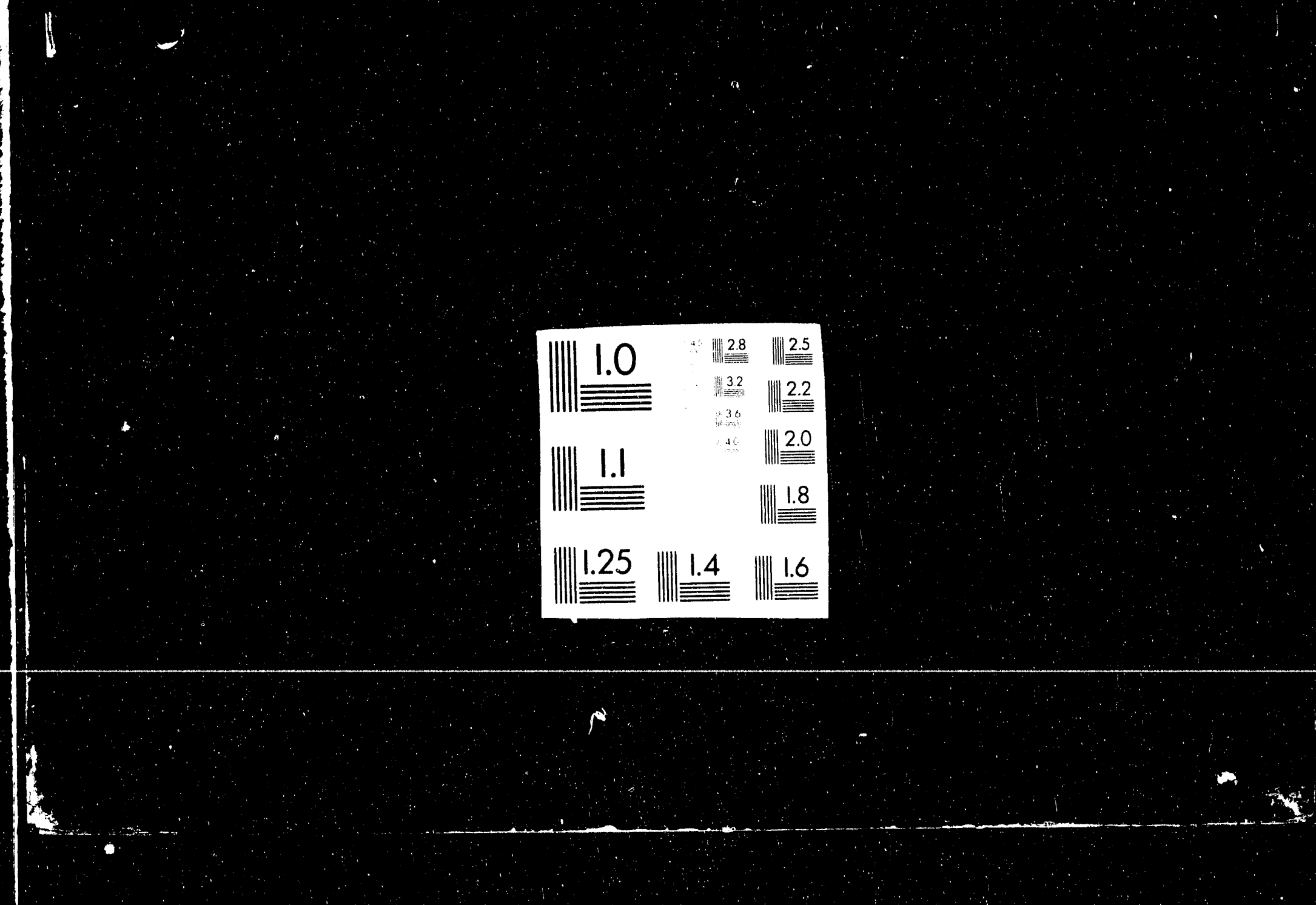


\section{ANALYTICAL ELECTRON MICROSCOPY STUDY.,F COLLOIDS FROM NUCLEAR WA.STE GLASS REACTIOP'"}

ANL/CMI/CP-76239

DE93 006403

E. C. Buck, J. K. Bates, J. C. Cunnane, W. L. Ebert, $\mathrm{X}$. Feng, and D. J. Wronkiewicz

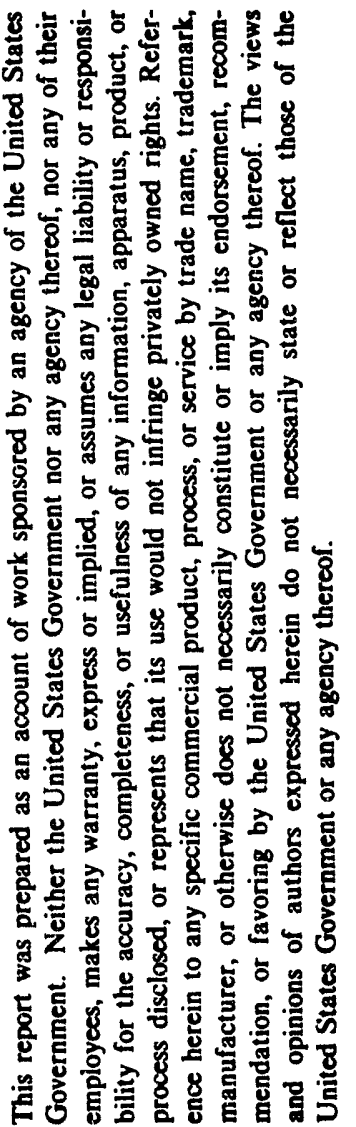

Argonne National Laboratory

9700 South Cass Avenue

Argonne, IL 60439-4837

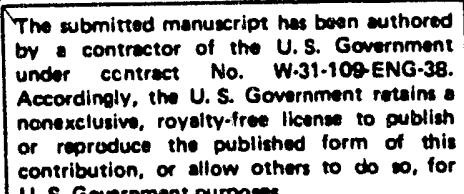

Submitted to

1992 Fall Materials Research Society Meeting

Scientific Basis for Nuclear Waste Management Symposium Boston, MA

November 30-December 4, 1992

*Work supported by the U.S. Department of Energy, Office of Environmental

Restoration and $W$ aste Management, under Contract W-31-109-ENG-38. 


\title{
ANALYTICAL ELECTRON MICROSCOPY STUDY OF COLLOIDS FROM NUCLEAR WASTE GLASS REACTION
}

\author{
E.C.BUCK, J.K.BATES, J.C.CUNNANE, W.L.EBERT, \\ X.FENG AND D.J.WRONKIEWICZ \\ Chemical Technology Division, Argonne National Laboratory, 11-60439
}

\begin{abstract}
An Analytical Electron Microscopy study of colloidal particles formed during reaction of waste glass has been performed. The effect of waste glass test parameters on colloid formation is examined. Characterization of phases present in the leachate of these tests has shown that layers spalled from the glass and precipitated phases are both sources of colloids in the leachate. Elements, such as uranium, have been found to concentrate within colloidal particles in the leachate.
\end{abstract}

\section{INTRODUCTION}

Secondary phases forming on the surface of reacted waste glass have been characterized by Analytical Electron Microscopy (AEM) [1,2]. Small particles such as colloids may also be identified using this instrument [3]. This paper aims to demonstrate the use of the AEM in characterizing colloidal material in the leachates of waste glass tests and provide data on the conditions necessary for the formation of stable colloids.

Colloids have the potential to increase the release of radionuclides from waste materials into the environment. Most studies on nuclear waste colloids have concentrated on the adsorption of actinides on groundwater colloids or hydrolysis of actinides leading to colloid formation $[4,5]$. The formation of both these types of colloids will be controlled by an initial solubility-ratedetermining step [6]. However, colloidal particles produced as a direct result of the alteration of the waste glass itself (i.e., via spallation), will not be dependent on such a step. This process has been shown to occur during simulated weathering of nuclear waste glass; the particles produced have been found to adsorb americium and plutonium $[7,8]$.

\section{EXPERIMENTAL}

Unfiltered leachates were collected from a number of different waste glass tests. A small quantity of leachate was extracted shortly after the experiment was terminated and a drop of the leachate was wicked through a 'holey' carbon grid with ethanol, in a modification to the method described by Wells and Goldberg, who recently utilized the TEM to examine sea water colloids $<50 \mathrm{~nm}$ in diameter [9] and also Cunnane and Bates, who investigated colloids from waste glass reactions[8]. Artifacts linked to this method of sample preparation may have resulted in coagulation or redox modifications [3]. Controls were run to determine possible particulate contamination routes. Soluble salts, such as sulfates and sodium chloride, were often found to precipitate on the grid, due to small droplets of leachate evaporating on the surface of the carbon film. Contaminants on the 'as-received' grids were usually easily recognized in the microscope as being large particles, often single crystal.

Analyses were performed using a JEOL 2000FXII Transmission Electron Microscope (TEM) operating at $200 \mathrm{kV}$, equipped with two Energy Dispersive X-ray detectors (EDS), including a light element detector and also a Gatan 666 Parallel Electron Energy Loss Spectrometer (EELS). Clay colloids can be readily identified in the TEM, as they often produce oblique textured electron diffraction (OTED) patterns when tilted. OTED patterns result when clay crystallites settle onto the 'holey' carbon grid with $c^{*}$ perpendicular to the carbon film ( $c$ in a monoclinic unit cell is not perpendicular to $\mathbf{a}$ and $\mathbf{b} ; \mathbf{c}^{*}$ is by convention). The resulting reciprocal lattice is a series of concentric circles lying on top of one another which, when tilted, resuit in the Ewaid sphere passing through an ellipse[10]. The small variations in the angle of the textured axis between clay colloids result in arcs rather than diffraction spots being produced. 
Calculated d-spacings from selected area electron diffraction (SAED) patterns were compared with X-ray diffraction data from the literature in combination with EDS data for phase identification. A limited clay colloidal data base was made from kaolinite and smectite samples, for comparison with experimental data. It is known that the electron microscope environment ( $1 \times 10^{-}$ $\left.{ }^{5} \mathrm{~Pa}\right)$ often reduces all clay $\mathrm{c}$-axis spacings to around $1 \mathrm{~nm}$ by removal of interlayer water [11], implying that the determination of $\mathrm{c}$ using OTED patterns would lead to this erroneous result.

\section{RESULTS}

The aim of this study was to identify and characterize colloidal material. Data on size distributions were not possible with the specimen preparation technique used. However, qualitative estimates of amounts of colloidal material were possible and it has been possible to relate test parameters to colloid formation. The results section is broken into two parts; effect of waste glass test parameters on colloid formation and the identification of colloidal phases.

\section{Effect of Waste Glass Test Parameters on Colloid Formation}

Fully radioactive $200 \mathrm{R}$ glass [12] reacted at a surface area to leachate volume ratio (SA/V) of $340 \mathrm{~m}^{-1}$ showed a steady increase in complexity and amount of clay colloidal material with time between 56 days and 364 days (see figure 1 ).
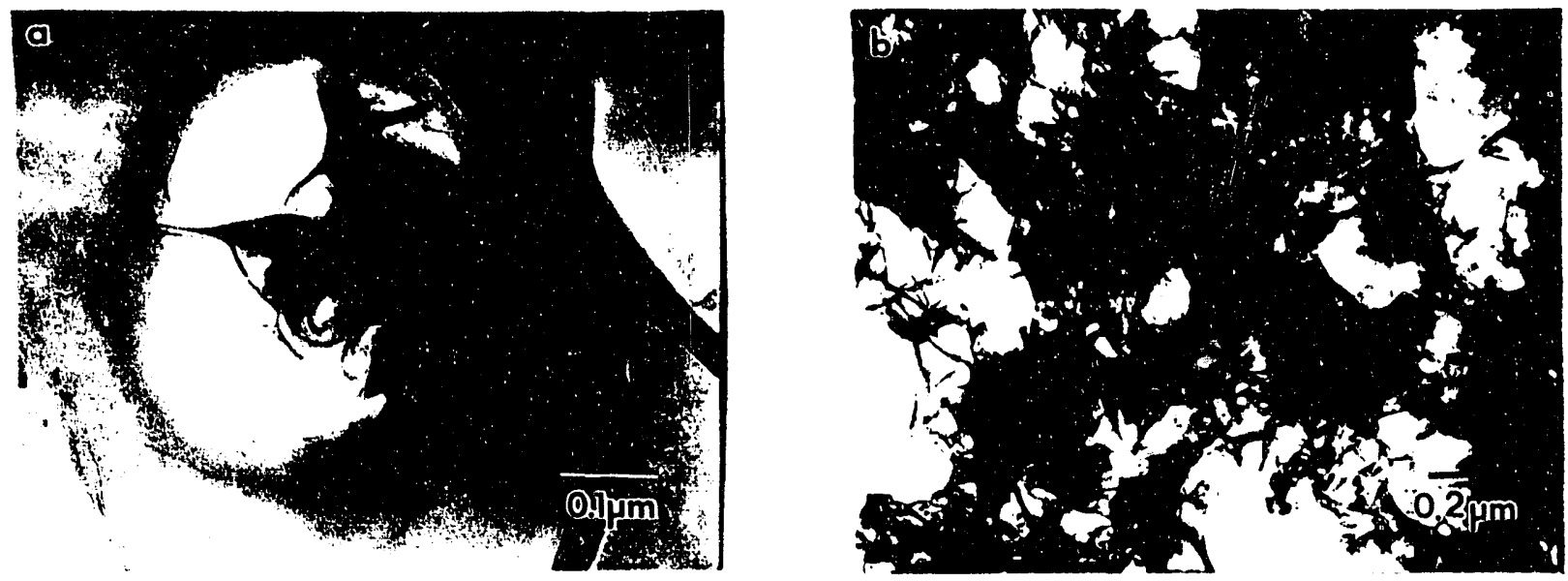

Figure 1. Micrographs showing colloidal material from the leachate of $200 \mathrm{R}$ glass reacted at $340 \mathrm{~m}^{-1}$ (reacted for (a) 182 and (b) 364 days).

The clay colloids were rich in the alkalis sodium and potassium, unlike the clays found in the reacted glass layers, which are depleted in these elements [12]. At 56 days, no clay material was found. By 182 days, a few crystalline clay colloids were visible. These were so thin that EDS composition data were difficult to obtain. The clay was found to be an iron potassium sodium aluminum silicate (montmorillonite). The material was so crystalline at 364 days that electron diffraction information on the $00 l$ lines was obtained. Images of the clay lattice fringe were also possible. The composition was basically the same as that in the 182-day test. Very little colloidal material was visible after long reaction times ( $>500$ days). The same set of experiments with simulated $200 \mathrm{~S}$ glass prnduced very little colloidal material at long reaction times.

SRL202U plasses [12] were reacted at different SAV ratios in Teflon containers in MCC-1 and PCT type tesis (described in detail elsewhere [14]) Each experiment was conducted in deionized water (DIW) and tuff groundwater solution (referred to as EJ-13). In order to investigate the effect of these three test parameters on leachate colloids, a number of AEM analyses were performed. Table.I shows an abbreviated matrix of tests. 

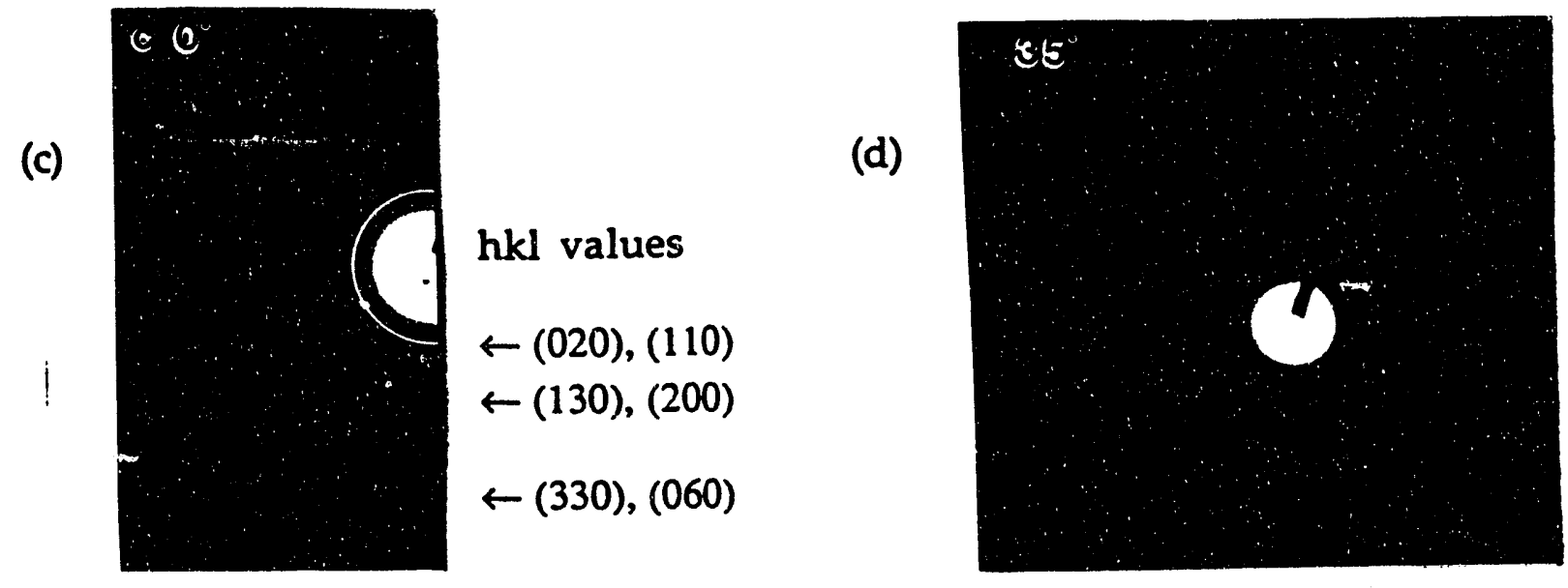

Figure 1 (cont.) Examples of OTED patterns of smectite (montmorillonite) type clay colloids can also be seen (c). At $0^{\circ}$ tilt the pattern is circular but as the grid is tilted a turbostratic oblique pattern appears, which is characteristic of well dispersed poorly crystalline dioctahedral smectites [13] (d). One can recognize the monoclinic unit cell of the clay from the ring pattern, as the spacings of the $h k 0$ reflections are not equally spaced.

In general, a smaller amount of colloidal material was found in tests run at the larger SA/V. The amount of colloidal material increased initially with time of reaction but then dropped to low levels. The occurrence of this decrease in colloids depended on the SAVV. At high SAVV $\left(20000 \mathrm{~m}^{-1}\right)$ the drop-off occurred at around 100 days. For $2000 \mathrm{~m}^{-1}$ experiments it was at around 200 days and for experiments run at $340 \mathrm{~m}^{-1}$, loss of colloidal material in the leachate occurred after 300-400 days. Later, other crystalline phases such as uranium silicates were observed. For the short term experiments, the material was only weakly crystalline and often the EDS signal was not great enough for an identification to be made. Micrographs show a few examples of colloids from these experiments (see figure 2 ).

Uranium was detected in the tests run at SA/V $\geq 2000 \mathrm{~m}^{-1}$ in both DIW and EJ-13 tests. Uranium rich regions were found by observing darker contrast in the TEM, due to backscattering electrons. These uranium phases had a concentration of uranium of $-30 w t \%$. The nominal concentration of uranium in a $202 \mathrm{U}$ glass is under $2 \mathrm{wt} \%$.

Reaction in EJ-13 had a dramatic effect on leachate colloids. There was a large increase in the total amount of colloidal material. EJ-13 has a low ionic strength and thus, ionic strength differences between EJ-13 and DIW would be unlikely to explain the large difference in colloidal particle numbers, in terms of effects on the electric double layer. It is more likely that EJ-13 contains small colloids that act as nucleation centers for colloidal growth.

Table I. Part of the SRL202U glass test matrix

\begin{tabular}{|l|l|l|}
\hline SA/V & DIW & EJ-13 \\
\hline $20000 \mathrm{~m}^{-1}$ & TZ7(28days) & TZ38(28days) \\
\hline & TZ11(91days) & TZ43(182days) \\
\hline $340 \mathrm{~m}^{-1}$ & TW3(28days) & TW34(28days) \\
\hline & TW9(180days) & TW39(180days) \\
\hline
\end{tabular}



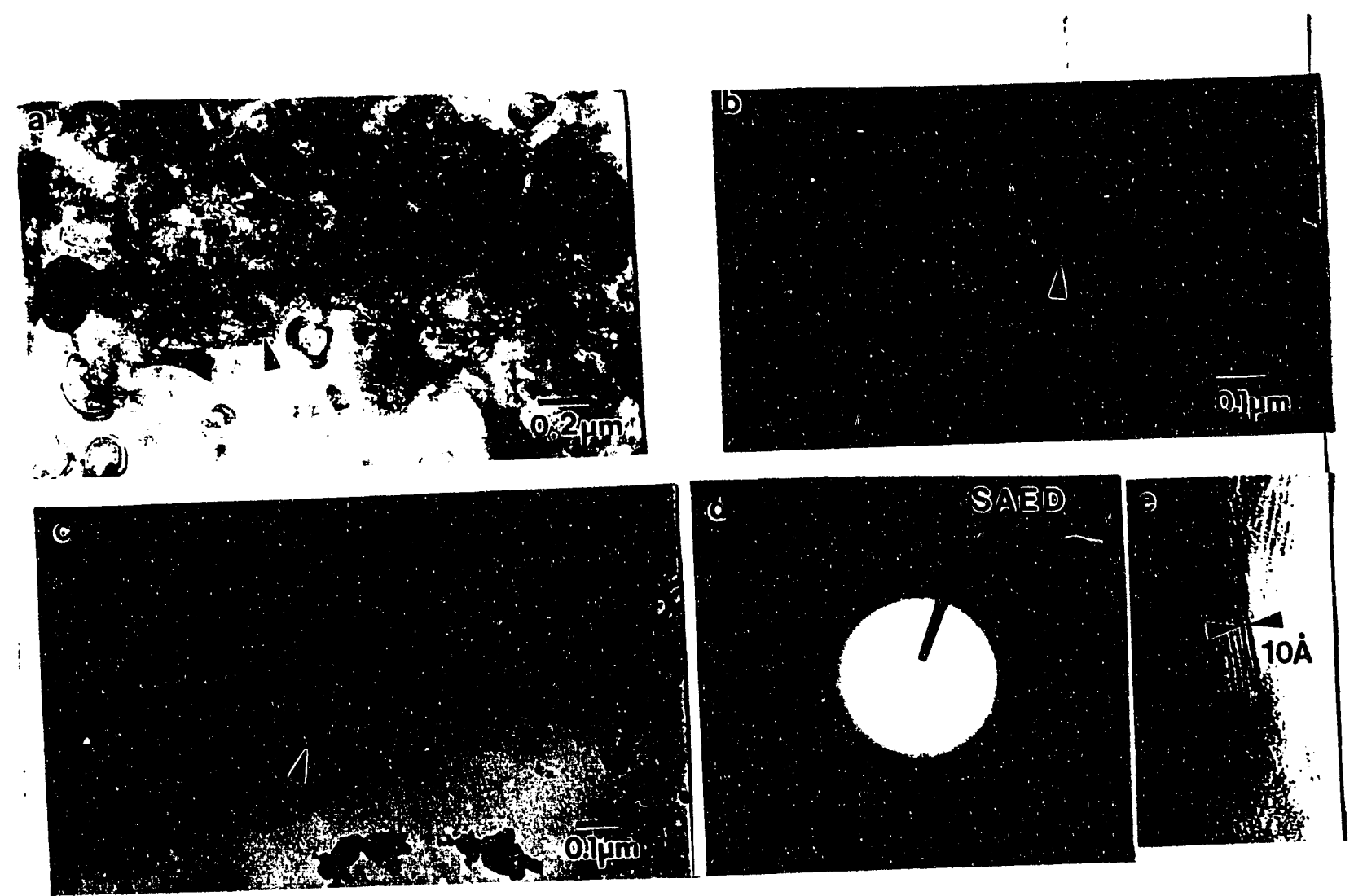

Figure 2. Colloids from reacted 202U glasses; (a) TZ11, (b) TW9, (c)TW39 (identified as montmorillonite), (d) SAED of clay from TW39, (e) micrograph showing c-basal spacings of $\sim 10 \AA$. The arrows point to colloidal material. The difference in clay morphology between figures 1 and 2 is due to clay orientation on the 'holey' carbon film.
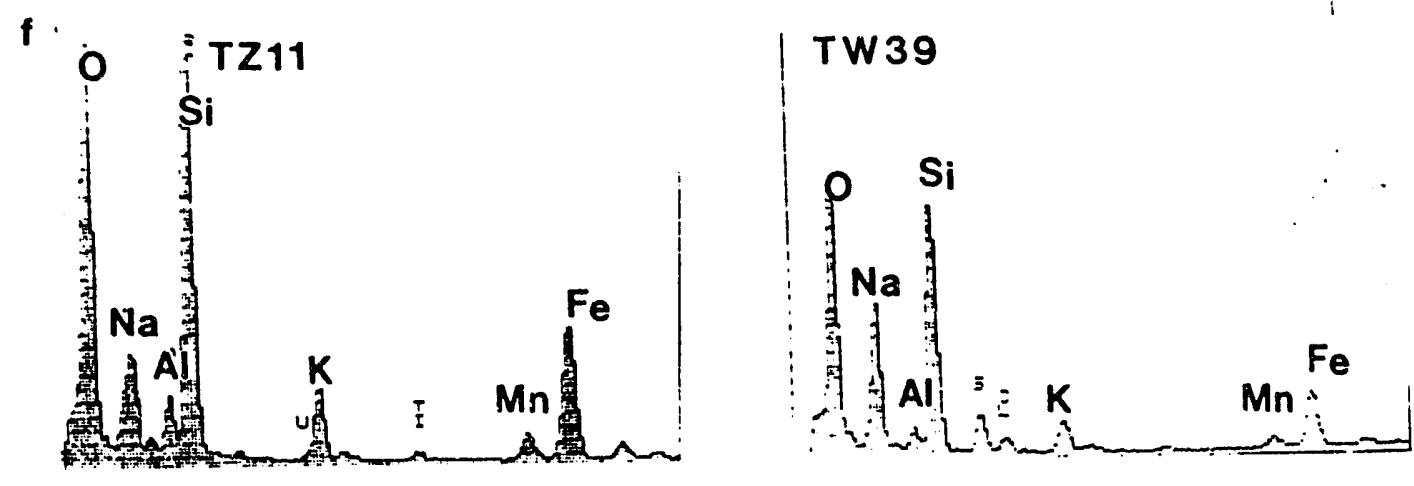

Figure 2 (cont.) (f) EDS compositions demonstrate the high alkali ( $\mathrm{Na}$ and $\mathrm{K}$ ) content in TZ11 and TW39.

\section{Identification of other Colloidal Phases}

A particle rich in calcium was found to contain strontium and harium from a 131 A glass [12] reacted at $340 \mathrm{~m}^{-1}$ and 360 days (figure $3 \mathrm{a}$ ). This phase was identified as the zeolite, heulandite, ideally, $\left(\mathrm{M}^{2+} \mathrm{Al}_{2} \mathrm{Si}_{7} \mathrm{O}_{18} \cdot 6 \mathrm{H}_{2} \mathrm{O}\right)$. Other phases were found such as; smectite, dolomite and calcite in the leachate of this test. The composition and d-spacings for the zeolite phase are shown in Tables II and III respectively. 
The EELS plot using the 'second difference' technique for detecting low levels of elements, shows the presence of strontium ( $\mathrm{Sr}-\mathrm{L}_{2.3}$ edges; $1940 \mathrm{eV}$ and $2007 \mathrm{eV}$ ) and also the silicon $\mathrm{K}$-edge at $1839 \mathrm{eV}$ in the colloid (see figure 3b). Three spectra were recorded at increasing energy offset $(\sim 6 \mathrm{eV})$. This technique removes the channel to channel gain variation that occurs with parallel detectors [15].

Table II. Composition of zeolite phase from the leachate of a $131 \mathrm{~A}$ glass test.

\begin{tabular}{|l|l|l|}
\hline El & Atom\% & wt\% \\
\hline $\mathrm{Si}$ & 53.5 & 50.5 \\
\hline $\mathrm{Al}$ & 31.2 & 29.0 \\
\hline $\mathrm{Ca}$ & 13.1 & 17.6 \\
\hline $\mathrm{Fe}$ & 1.5 & 2.8 \\
\hline
\end{tabular}

a

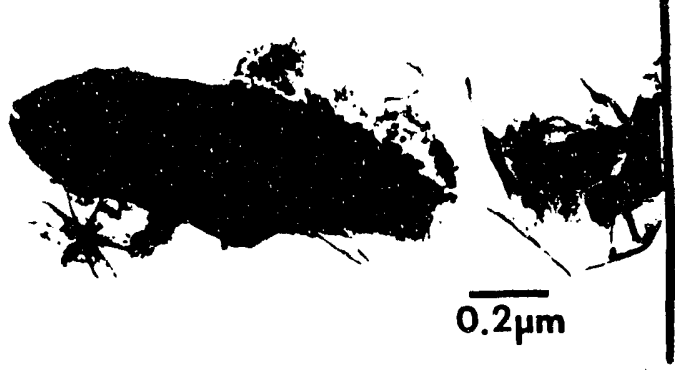

Table III. Electron diffraction data on zeolite phase (including errors).

\begin{tabular}{|l|l|l|}
\hline$d \AA$ & $\pm \AA$ & $\begin{array}{l}\text { JCPDS- } \\
21-131\end{array}$ \\
\hline 4.37 & 0.08 & 4.36 \\
\hline 3.79 & 0.06 & 3.72 \\
\hline 3.26 & 0.05 & 3.19 \\
\hline 2.44 & 0.04 & 2.43 \\
\hline 2.15 & 0.03 & 2.12 \\
\hline
\end{tabular}

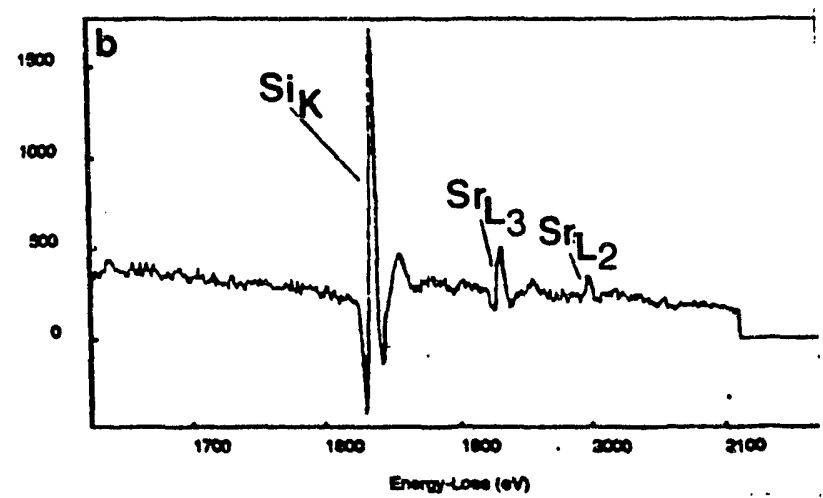

Figure 3. (a) micrograph of colloid and (b) a second difference EELS of a Sr containing colloid
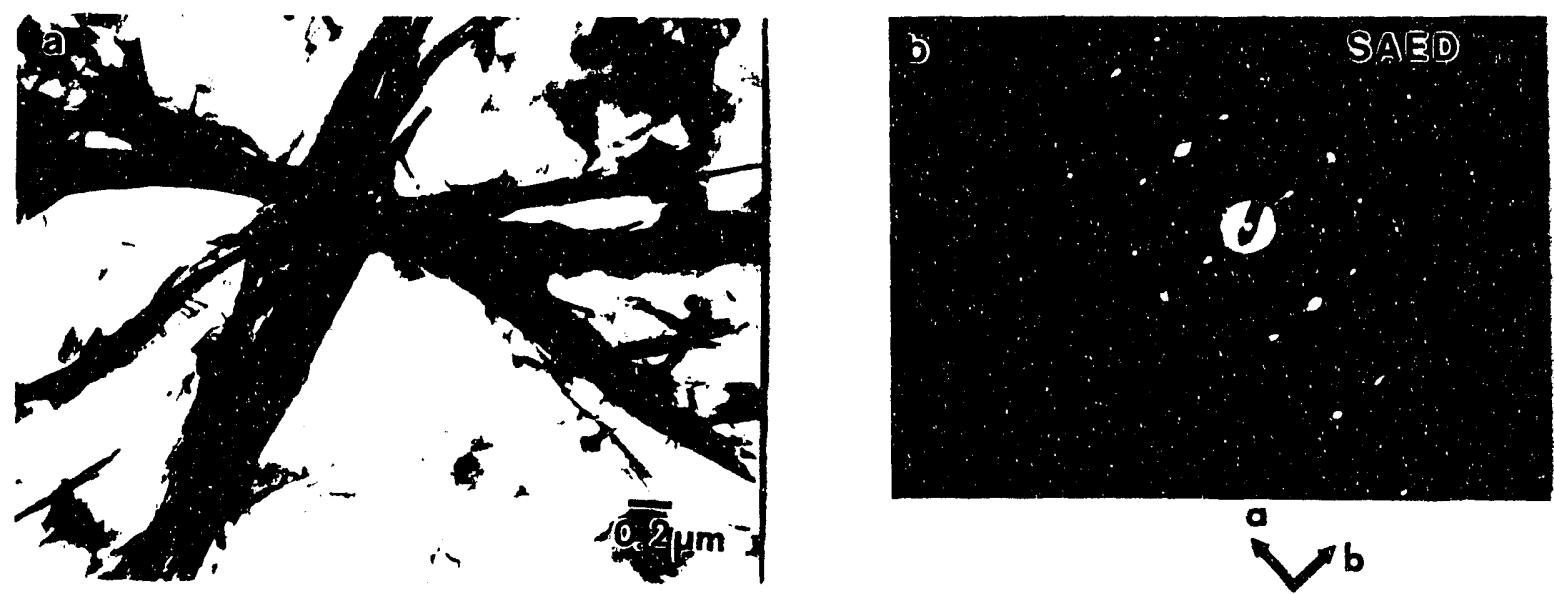

Figure 4. Identification of a uranium silicate colloid (weeksite) by; (a) image, (b) SAED (the major zone axis is $\mathrm{B}[001])$. 


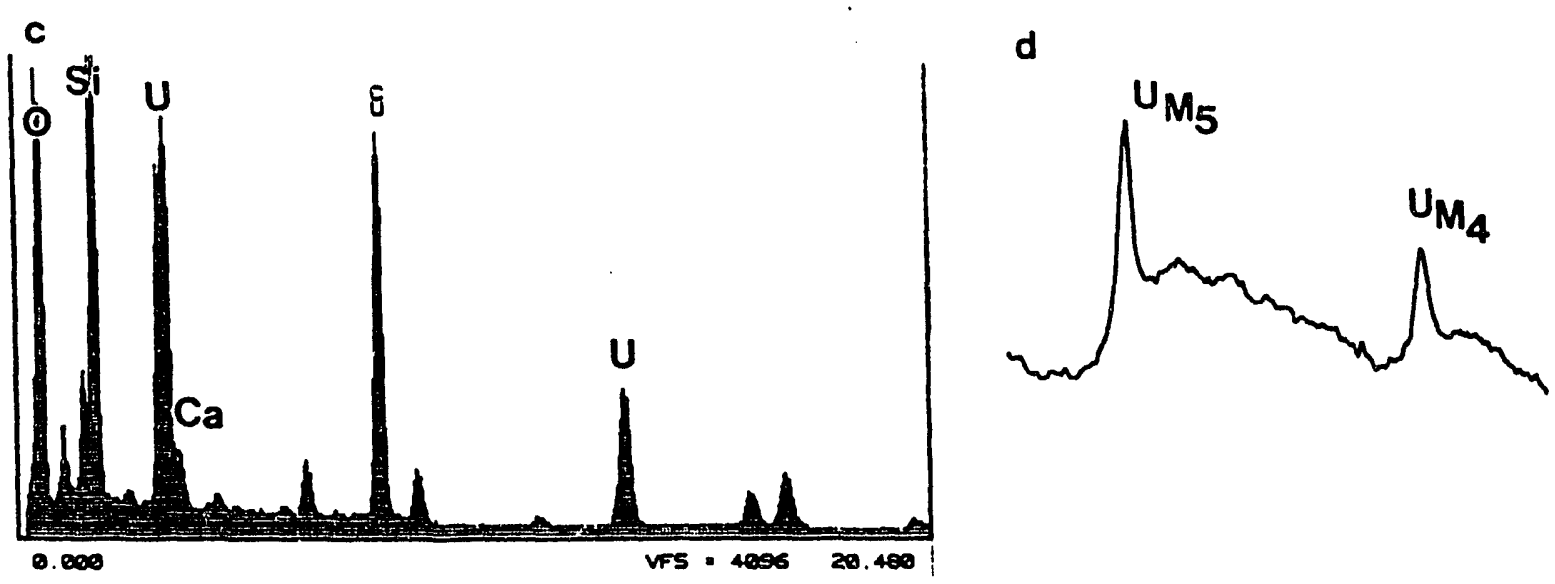

Figure 4 (cont.) (c) EDS and (d) EELS of uranium silicate particle. The colloid was found in the leachate of a SRL131A glass reacted at $2000 \mathrm{~m}^{-1}$ for 560 days.

Uranium silicate phases were observed in all glass tests after -360 days of reaction (see figure 4). These colloids appeared suddenly, suggesting that they were formed via spallation processes. They were often found in association with clay particles. Electron diffraction and EDS composition of the phase was consistent with the uranium silicate mineral, weeksite, $\left(\mathrm{K}_{2}\left(\mathrm{UO}_{2}\right)_{2} \mathrm{Si}_{6} \mathrm{O}_{15} .5 \mathrm{H}_{2} \mathrm{O}\right)$. These phases were found to be extremely beam sensitive probably due to the water content in them (i.e., rapid beam damage probably occurred via a combination of radiolysis and displacement events). They display the characteristic uranium silicate morphology of elongated crystallites.

Uranium $\mathrm{M}_{4,5}$ absorption edges at 3552 and $3728 \mathrm{eV}$ are shown in figure $4 \mathrm{~d}$. It was found that the severe intensity and the long integration times required to yield information from these deep edges, was such that the colloid became amorphous. These spectra have not been deconvoluted to remove multiple scattering effects. This region of the energy spectrum, when used with second difference techniques (as described earlier), could be used to detect low levels of other transuranics. In figure $5 \mathrm{c}$ this has been attempted however no transuranics are observable above the background signal.

a

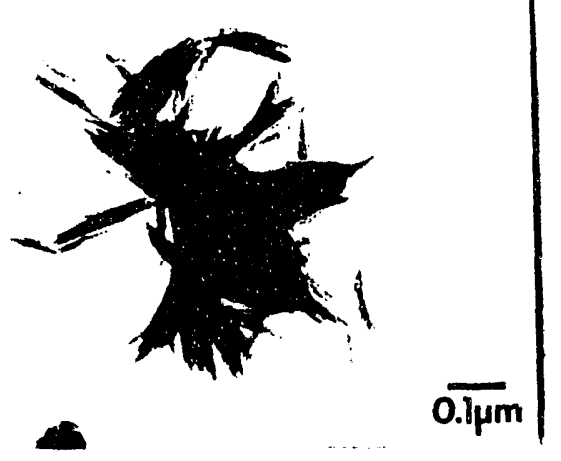

Figure 5. (a) Micrograph of the uranium titanium phase, (b) SAED of the colloids and (c) a second difference electron energy loss spectrum, used to detect low levels of the $\mathrm{M}$-lines of actinides; none are visible except that of the uranium $\mathrm{M}_{4,5}$-edges.
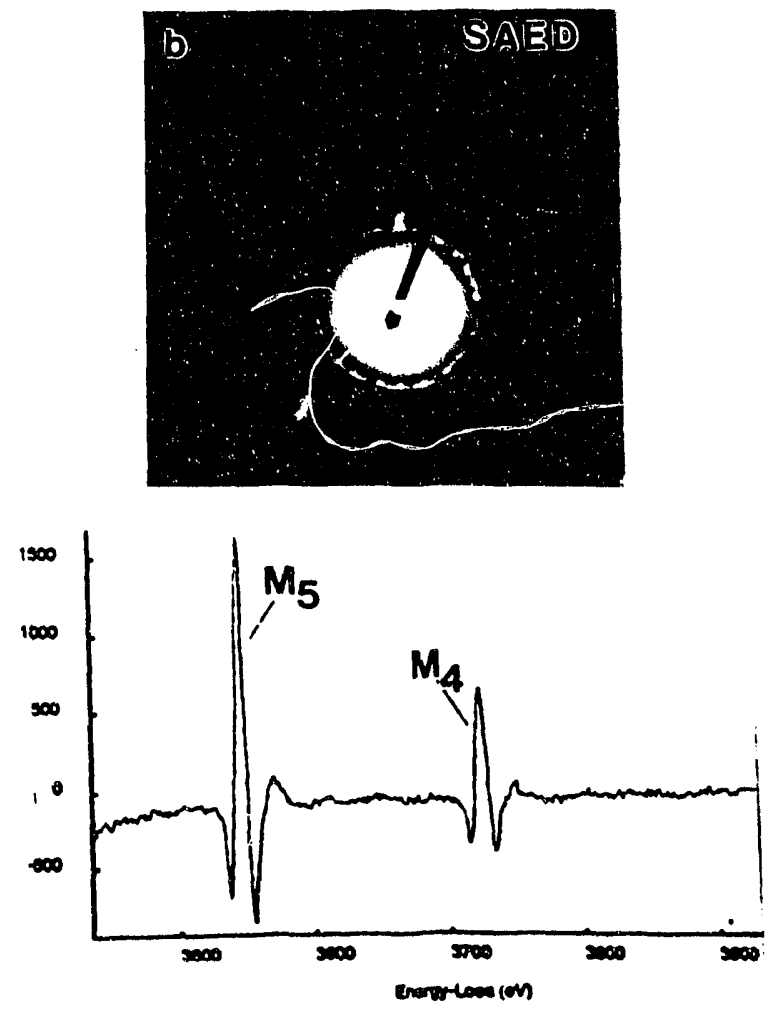
Colloids formed in glasses reacted in $\mathrm{EJ}-13$ water at $340 \mathrm{~m}^{-1}$ and exposed to a gamma radiation field [16] were found to be more crystalline than any other leachate colloids. Examination of a $131 \mathrm{~A}$ glass [12] reacted for 180 days at $90^{\circ} \mathrm{C}$ revealed crystalline iron oxide and magnesium silicate colloids. A uranium titanium phase was also found (see figure 5a). The regular shape of these uranium phases suggested that they should have been crystalline; however very few electron diffraction spots were observed (see figure $5 \mathrm{~b}$ ). The phase was not observed in longer reacted tests. Similar phases have been observed in the surface layers of leached 131 glasses and the phase was tentatively identified as brannerite [17]. The uranium titanium phases were $0.1 \mu \mathrm{m}$ in length, they were isolated from all other colloidal material, which suggested that they had formed within the leachate.

\section{DISCUSSION}

The preparation of TEM samples from waste glass leachates is a harsh process, which results in the production of artifacts; but these artifacts are recognizable, and with comparative light scattering and filtration studies, the results of TEM investigations can be interpreted to yield information on the behavior of colloids in the leachate. Light scattering investigations by Feng et al have demonstrated that colloids produced during waste glass dissolution range in their mean size from $1 \mu \mathrm{m}$ to $0.4 \mu \mathrm{m}$, depending on the $\mathrm{pH}$ of the leachate [18]. Cunnane and Bates, using filtration rechniques and TEM determined the size ranged from $1 \mu \mathrm{m}$ to $3.8 \mathrm{~nm}$ for colloids produced during waste glass reaction [8].

Feng also monitored the physical properties of leachate colloidal material with time, salt concentration and $\mathrm{pH}[18]$. As salt content is increased the electric double layer is compressed, leading to flocculation of colloids and eventual sedimentation by van der Waals attractive forces[19]. SA/V may be affecting colloidal stability through its effect on leachate salt concentration. For example, at high SAV or long reaction times the resulting high salt concentrations may prevent colloidal growth; as sedimentation occurs before fulliy crystalline colloids can develop. For a complete explanation of the effects of solution conditions on colloidal stability more factors have to be included, such as $\mathrm{pH}$, all of which would require detailed modeling to comprend.

The absence of uranium rich colloids in the smaller SAV experiments may be due to the effect of $\mathrm{pH}$ on the solubility of uranium. At the higher $\mathrm{pH}$ (higher SA/V), uranium will undergo hydrolysis and real colloid formation. These colloids may then be adsorbed onto the clay colloids present in the leachate. At the lower SA/V, uranium will be less liable to undergo colloid formation.

The uranium silicate colloids tended to appear abruptly in leachates after various reaction times depending on SAVV; small uranium silicate colloids were not observed in earlier tests, which would have suggested growth in solution (this may be due to the sampling timing). If spallation has occurred in these batch tests, it has most likely happened during sampling. Spalled colloids could possibly be recognized by having bits of clay attached to them. The exception to this were the $0.1 \mu \mathrm{m}$ uranium titanium colloids, which appear to have formed in the leachate. The concentrating of radioactive elements within colloids clearly shows the need to carry out investigations with fully radioactive production glasses, so that correct models for the release rate of radionuclides from waste glass can be generated. These types of investigations enable one to determine the more mobile elements and the mobile forms/phases.

The results from these AEM studies can also provide valuable data for the modeling of colloid migration away from waste glass. The migration of colloids will depend on their physical properties, such as phase type and morphology. Experimental techniques to determine the size distribution of colloids and their rate of diffusion using the Stokes-Einstein theory, generally assume that the colloids are spherical [20]; this study has shown that leachate colloids are usually planar or elongated. This finding should be included in efforts to model colloidal migration. 


\section{CONCLUSION}

The clays and other colloids found in the leachate are a new source of colloids for actinides to adsorb onto. Uranium has been found almost exclusively in discrete phases, such as weeksite, these may be the result of spallation. This work has demonstrated that colloids are produced during waste glass dissolution and that these often contain radioactive elements. The TEM with its analytical and diffraction capabilities has been shown to be a useful tool for characterizing colloidal material.

\section{ACKNOWLEDGEMENTS}

Work supported by the U.S. Department of Energy, Office of Environmental Restoration and Waste Management, under Contract W-31-109-ENG-38.

\section{REFERENCES}

1. J.K.Bates, W.L.Ebert, J.J.Mazer, J.P.Bradley, C.R.Bradley, and N.L.Dietz in Scientific Basis for Nuclear Waste Management, edited by T.Abrajano and L.H.Johnson, (Mater. Res. Soc. Proc., 212, Boston,MA , 1990) pp. 77-87.

2. W.L.Ebert and J.K.Bates in Scientific Basis for Nuclear Waste Management, edited by T.A.Abrajano and L.H.Johnson, (Mater. Res. Soc. Proc., 212, Boston,MA ,1990) pp. 89-98.

3. D.Perret, G.G.Leopard, M.Müller, N.Belzile, R.de Vitre and J.Buffle, Water Research, 25, 1333-1343 (1991)

4. J.D.F.Ramsey, Radiochimica Acta, 44/45, 165-170 (1988).

5. J.I.Kim, Radiochimica Acta, 52/53, 71-81 (1991).

6. H.Nitsche, Radiochimica Acta, 52/53, 3-8 (1991).

7. J.K.Bates, J.P.Bradley, A.Teetsov, C.R.Bradley and M.Buchholtz ten Brink, Science, 256, 649-651 (1992).

8. J.C.Cunnane and J.K.Bates in 93rd Annual Meeting, American Ceramics Society, Cincinnati, OH (1991).

9. M.L.Wells and E.D.Goldberg, Nature, 353, 342-344 (1991).

10. J.A.Gard in Electron Microscopy in Mineralogy, edited by H-R Wenk, (SpringerPublishers, Berlin, 1976) p. 52.

11. D.R.Veblen, G.D.Guthrie, K.J.T.Livi and R.C.Reynolds, Clays and Clay Minerals, 38, 1-13 (1990).

12. J.K.Bates, W.L.Ebert, X.Feng and W.L.Bourcier, J.Nuc.Mat, 190, 198-227 (1992).

13. V.A.Dritz in Electron Diffraction and High Resolution Electron Microscopy of Minerals, (Springer-Publishers, 1983) p.150

14. W.L.Ebert, J.K.Bates, C.R.Bradley and E.C.Buck, in these proceedings (1992).

15. O.L.Krivanek and M.K.Kundmann in International Symposium on Electron Microscopy, edited by K.Kuo and J.Yao (Beijing, China,1991) pp381-390.

16 D.J.Wronkiewicz, J.E.Young and J.K.Bates, in Scientific Basis for Nuclear Waste Management, edited by T.A.Abrajano and L.H.Johnson, (Mater. Res. Soc. Proc., 212, Boston,MA ,1990) pp. 99-106.

17. T.A.Abrajano, J.K.Bates, J.P.Bradley and W.L.Bourcier, Clays and Clay Minerals, 38, 537 (1990).

18. X.Feng, E.C.Buck, C.Mertz, J.K.Bates and J.C.Cunnane, accepted for putlication at 'Vaste Managment'93, Tuscon, AZ.

19. J.van Olphen in Clay Colloid Chemistry (John Wiley Publishers, New York, 1977) p.29.

20. I.R.Triay, D.E.Hobart, A.J.Mitchell, T.W.Newton, M.A.Ott, P.D.Palmer, R.S.Rundberg and J.L.Thompson, Radiochimica Acta, 52/53, 127 (1991). 

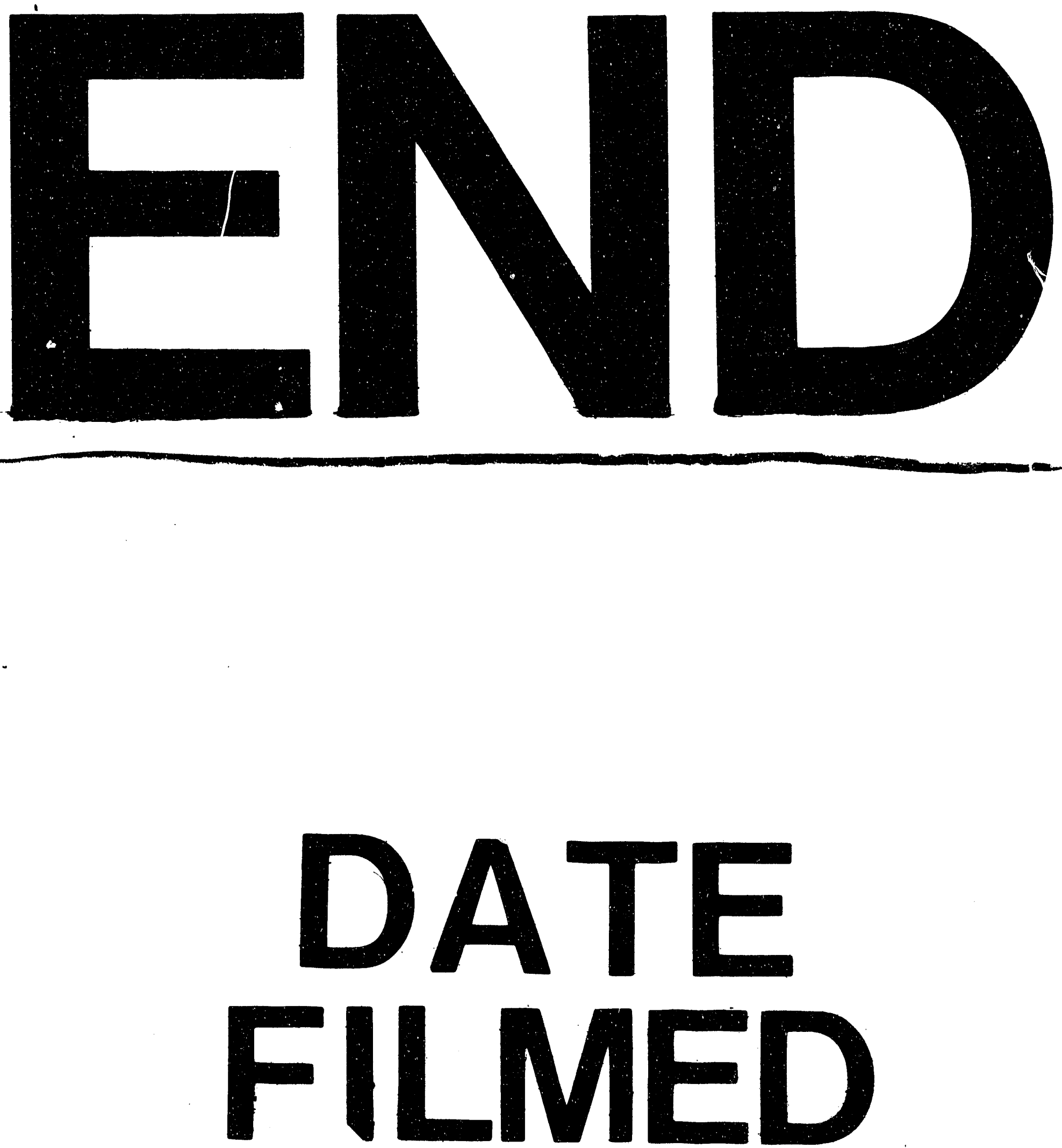

I

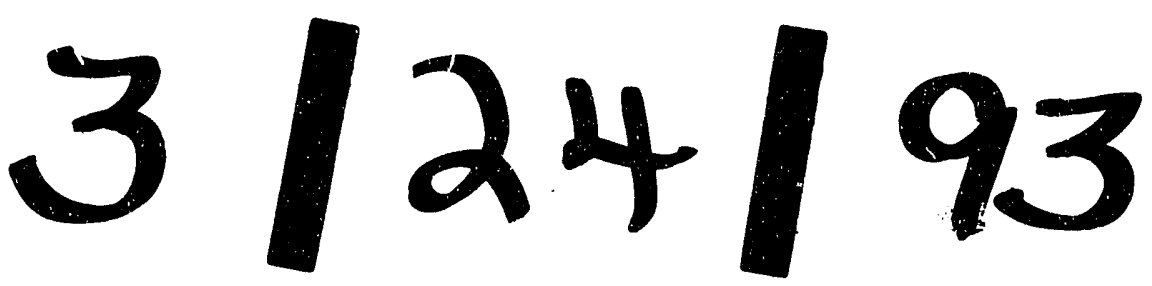


